\title{
Performance of transperineal template-guided mapping biopsy in detecting prostate cancer in the initial and repeat biopsy setting
}

\author{
AV Taira ${ }^{1}$, GS Merrick², RW Galbreath ${ }^{2}$, H Andreini ${ }^{3}$, W Taubenslag ${ }^{3}$, R Curtis $^{3}$, WM Butler ${ }^{2}$, \\ E Adamovich ${ }^{4}$ and KE Wallner ${ }^{5}$ \\ ${ }^{1}$ Department of Radiation Oncology, University of Washington, Seattle, WA, USA; ${ }^{2}$ Schiffler Cancer Center, Wheeling Jesuit \\ University, Medical Park, Wheeling, WV, USA; ${ }^{3}$ Department of Urology, Wheeling Hospital, Medical Park, Wheeling, WV, USA; \\ ${ }^{4}$ Department of Pathology, Wheeling Hospital, Medical Park, Wheeling, WV, USA and ${ }^{5}$ Puget Sound Healthcare Corporation, \\ Group Health Cooperative, Department of Radiation Oncology, University of Washington, Seattle, WA, USA
}

\begin{abstract}
Transrectal ultrasound (TRUS) biopsy can miss $20-30 \%$ of clinically significant cancers. We evaluate an alternative approach-transperineal template-guided mapping biopsy (TTMB) in the initial and repeat biopsy setting. From January 2005 through September 2008, 373 consecutive men underwent TTMB (294 men with $\geqslant 1$ prior negative biopsy and 79 men as the initial biopsy). The location of each positive biopsy core, number of positive cores, and percent involvement of each core was recorded. Cancer detection rate for the initial biopsy was $75.9 \%$. For men with 1,2 , and $\geqslant 3$ prior negative biopsies detection rates were $55.5 \%, 41.7 \%$, and $34.4 \%$, respectively. In all, $55.5 \%$ of the cancers identified were Gleason $\geqslant 7$. The majority of the cancers were multifocal. There was no significant change in the number of positive cores or Gleason score as the number of prior biopsies increased. The anterior and apical aspects of the prostate were among the most common cancer locations. TTMB provides a high rate of cancer detection as initial and repeat biopsy. TTMB was particularly effective at diagnosing anterior and apical cancer. TTMB may have particular application for men considering active surveillance, with prior negative TRUS biopsies, and those considering subtotal gland or other minimally invasive treatments.

Prostate Cancer and Prostatic Diseases (2010) 13, 71-77; doi:10.1038/pcan.2009.42; published online 29 September 2009
\end{abstract}

Keywords: biopsy; mapping biopsy; Gleason score

\section{Introduction}

Transrectal ultrasound (TRUS)-guided biopsy using a 12-core scheme is the standard biopsy approach for men with suspected prostate cancer. Among the benefits of TRUS-guided biopsy is its fairly good sensitivity, its ability to be performed during a clinic visit, and the lack of significant morbidity associated with the procedure.

TRUS biopsy-particularly with the 12-core approach-provides a reasonable sampling of the prostate gland. Nonetheless, a significant minority of men with an initial negative biopsy are found to have prostate cancer on subsequent biopsies. ${ }^{1,2}$ In addition, initial biopsy pathology frequently underestimates the Gleason score that would be assigned based on full gland evaluation. ${ }^{3}$ In an effort to reduce false-negative rates and improve accuracy of staging, investigators have explored alternative biopsy approaches, including increasing the number of cores sampled and changing access with a transperineal approach.

Correspondence: Dr GS Merrick, Schiffler Cancer Center, Wheeling Hospital, 1 Medical Park, Wheeling, WV 26003, USA.

E-mail: gmerrick@urologicresearchinstitute.org

Received 15 June 2009; revised 23 July 2009; accepted 23 August 2009; published online 29 September 2009
Transperineal biopsy, particularly when performed with a standardized template, provides reliable access to the entire prostate gland. Also, because templatebased transperineal biopsies are conducted under general or regional anesthesia, a larger number of cores are typically obtained. We report our experience with transperineal template-guided prostate mapping biopsy (TTMB) as initial biopsy and in the setting of repeat biopsy. We focus on rate of cancer detection, relative portion of potentially insignificant cancers identified, and location of new cancers identified.

\section{Materials and methods}

From January 2005 through September 2008, 373 consecutive men underwent TTMB by means of an anatomic-based technique with sampling of 24 prostate regions. TTMB was originally used at our institution only for men who had undergone at least one prior negative biopsy, but had persistently elevated prostate specific antigen (PSA) and/or a diagnosis of atypical small acinar proliferation or multifocal high-grade prostatic intraepithelial neoplasia on prior biopsy. Eventually, as other institutions began publishing on use of the transperineal 
approach for initial biopsy, ${ }^{4,5}$ we began to offer TTMB to men as initial biopsy procedure for an elevated PSA. This study reports on 294 men who underwent TTMB as repeat biopsy and 79 men who had TTMB performed as initial biopsy.

The TTMB technique has been described in detail earlier. ${ }^{6}$ All biopsies were performed by a single operator (GM). Two days before the procedure, Tamsulosin (0.8 mg daily) was initiated and was continued for 2 weeks. TTMB was performed in the operating room using general anesthesia. All patients received perioperative antibiotics. The setup was the same as used for brachytherapy, with patients in the dorsal lithotomy position. The prostate was scanned from the level of the proximal seminal vesicles/base of the prostate to the apex using the $5.0-7.5 \mathrm{MHz}$ transducer (Sonoline; Seimens Inc., Issaquah, WA, USA). A volumetric ultrasonographic evaluation was obtained to estimate prostate size. In addition, the prostate gland and transition zone (TZ) volumes were estimated as an ellipsoid with the formula Length $\times$ Width $\times$ Height $\times 0.5236$.

Transperineal biopsies were obtained through template apertures corresponding with the 24 regional biopsy locations. For each of the 24 regions, one to three biopsy cores was taken, depending on prostate size. The 18 gauge, $25 \mathrm{~cm}$ long Max-Core biopsy needles (C.R. Bard Inc., Covington, GA, USA) were used. For each biopsy core, the template coordinate and the offset from base were recorded. Biopsy regions included posterior prostate $(3,4,12,13,21,22)$, posterior lateral $(2,5,11,14$, $20,23)$, anterior lateral $(1,6,9,10,15,16)$, anterior apex $(19,24)$, and TZ $(7,8,17,18)$ After completion of all sampling, patients underwent cystoscopic evaluation.

For each patient, the location of each positive biopsy core, the number of positive cores, and the percent involvement of each core was recorded. All pathologic review was performed at the same facility by an expert prostate pathologist (EA). Only patients with Gleason score $\geqslant 6$ were included as having been diagnosed with prostate cancer. Of the patients with Gleason 6 cancer, we wanted to separate out those with potentially insignificant disease-for whom watchful waiting would likely be the preferred option-from men with disease that would more seriously merit consideration of definitive treatment. Investigators at Johns Hopkins ${ }^{7}$ have shown that men who on presurgical saturation biopsy had no cores of Gleason $>6$, no core with $>50 \%$ involvement, PSA density $<0.15$, and fewer than three cores involved were very unlikely to have clinically significant disease on pathologic review after radical prostatectomy. Clinically insignificant disease for their purposes was defined as pathologic review of prostatectomy specimen with tumor $<0.5 \mathrm{~cm}^{3}$, organ confined, seminal vesicles and lymph nodes negative for tumor, and no Gleason pattern 4 or 5 . We used the same biopsy criteria as in that study to identify men with potentially insignificant disease.

One-way analysis of variance and two-sided Fisher exact test were used to determine the significance of differences between men undergoing initial versus repeat biopsies concerning clinical parameters and TTMB parameters. All data were analyzed with the use of Statistical Package for Social Sciences, version 14.0 (SPPS Inc., Chicago, IL, USA). Statistical significance was set at $P \leqslant 0.005$.

\section{Results}

Table 1 summarizes the clinical parameters of the study population, subdivided by the number of prior biopsies.

Table 1 Clinical parameters of the study population

\begin{tabular}{|c|c|c|c|c|c|c|c|c|c|c|c|}
\hline \multirow[t]{3}{*}{ Continuous variable } & \multicolumn{11}{|c|}{ Number of biopsy sessions } \\
\hline & \multicolumn{2}{|c|}{$1(\mathrm{n}=79)$} & \multicolumn{2}{|c|}{$2(\mathrm{n}=146)$} & \multicolumn{2}{|c|}{$3(\mathrm{n}=84)$} & \multicolumn{2}{|c|}{$\geqslant 4(\mathrm{n}=64)$} & \multirow[t]{2}{*}{$\mathrm{P}$} & \multicolumn{2}{|c|}{ Total $(\mathrm{n}=373)$} \\
\hline & Mean & Median & Mean & Median & Mean & Median & Mean & Median & & Mean & Median \\
\hline Age at biopsy & 62.7 & 63.9 & 63.0 & 62.5 & 64.1 & 64.0 & 66.4 & 66.5 & 0.011 & 63.8 & 64.2 \\
\hline Prebiopsy PSA & 5.6 & 4.8 & 7.0 & 5.4 & 9.1 & 8.6 & 13.6 & 9.3 & $<0.001$ & 8.3 & 6.3 \\
\hline Body mass index & 28.5 & 28.0 & 29.0 & 27.8 & 28.3 & 27.8 & 28.6 & 28.1 & 0.767 & 28.7 & 27.9 \\
\hline No. of prior biopsy cores & - & - & 13.7 & 12.0 & 25.3 & 20.0 & 37.9 & 30.5 & $<0.001$ & 22.3 & 12.0 \\
\hline Categorical variables & \multicolumn{2}{|c|}{ Count (\%) } & \multicolumn{2}{|c|}{ Count (\%) } & \multicolumn{2}{|c|}{ Count (\%) } & \multicolumn{2}{|c|}{ Count (\%) } & $\mathrm{P}$ & \multicolumn{2}{|c|}{ Count (\%) } \\
\hline Prebiopsy TURP & \multicolumn{2}{|c|}{$1(1.3)$} & \multicolumn{2}{|c|}{$0(0)$} & \multicolumn{2}{|c|}{$1(1.2)$} & \multicolumn{2}{|c|}{$5(7.8)$} & 0.001 & \multicolumn{2}{|c|}{$366(98.1)$} \\
\hline \multicolumn{12}{|l|}{ Prebiopsy diagnosis } \\
\hline PIN & \multirow{2}{*}{\multicolumn{2}{|c|}{$\begin{array}{c}0(0) \\
79(100)\end{array}$}} & \multicolumn{2}{|c|}{$9(6.2)$} & \multicolumn{2}{|c|}{$4(4.8)$} & \multicolumn{2}{|c|}{$5(7.8)$} & $<0.001$ & \multicolumn{2}{|c|}{$18(4.8)$} \\
\hline Elevated PSA & & & \multirow{2}{*}{\multicolumn{2}{|c|}{$\begin{array}{l}109(74.7) \\
28(19.2)\end{array}$}} & \multirow{2}{*}{\multicolumn{2}{|c|}{$\begin{array}{l}62(73.8) \\
18(21.4)\end{array}$}} & \multirow{2}{*}{\multicolumn{2}{|c|}{$\begin{array}{l}46(71.9) \\
13(20.3)\end{array}$}} & & \multirow{2}{*}{\multicolumn{2}{|c|}{$\begin{array}{c}296(19.4) \\
59(15.8)\end{array}$}} \\
\hline ASAP & \multicolumn{2}{|c|}{$0(0)$} & & & & & & & & & \\
\hline \multicolumn{12}{|l|}{ Tobacco } \\
\hline Never & \multicolumn{2}{|c|}{$38(48.1)$} & \multicolumn{2}{|c|}{$72(49.2)$} & \multicolumn{2}{|c|}{$40(47.6)$} & \multicolumn{2}{|c|}{$31(48.4)$} & 0.724 & 181 & (48.5) \\
\hline Former & & 39.2) & 53 & 36.3) & 35 & 41.7) & & 45.3) & & $14 \varepsilon$ & (39.7) \\
\hline Current & & 12.7) & 21 & 14.4) & & $0.7)$ & & 6.3) & & & 11.8) \\
\hline Hypertension & & 41.8) & 75 & 50.3) & 34 & 40.5) & & 50.0) & 0.377 & 17 & (46.3) \\
\hline Diabetes & & 3.8) & 24 & 16.4) & 11 & 13.1) & & 9.4) & 0.039 & & 11.8) \\
\hline
\end{tabular}

Abbreviations: ASAP, atypical small acinar proliferation; PIN, prostatic intraepithelial neoplasia; PSA, prostate specific antigen; TURP, transurethral resection of the prostate.

Bold indicates statistically significant. 
Table 2 TTMB parameters of the study population

\begin{tabular}{|c|c|c|c|c|c|c|c|c|c|c|c|}
\hline \multirow[t]{3}{*}{ Continuous variable } & \multicolumn{11}{|c|}{ Number of biopsy sessions } \\
\hline & \multicolumn{2}{|c|}{$1(\mathrm{n}=79)$} & \multicolumn{2}{|c|}{$2(\mathrm{n}=146$} & \multicolumn{2}{|c|}{$3(\mathrm{n}=84)$} & \multicolumn{2}{|c|}{$\geqslant 4(\mathrm{n}=64)$} & \multirow[t]{2}{*}{$\mathrm{P}$} & \multicolumn{2}{|c|}{ Total $(\mathrm{n}=373)$} \\
\hline & Mean & Median & Mean & Median & Mean & Median & Mean & Median & & Mean & Median \\
\hline No. mapping biopsy cores ${ }^{a}$ & 55.1 & 55.0 & 54.7 & 58.0 & 53.2 & 58.0 & 52.1 & 58.0 & 0.323 & 54.0 & 57.0 \\
\hline \multicolumn{12}{|l|}{ Prostate volume } \\
\hline Volumetric & 52.7 & 45.1 & 61.8 & 55.4 & 73.2 & 62.7 & 89.5 & 75.0 & $<0.001$ & 67.2 & 58.0 \\
\hline Ellipsoid & 46.2 & 39.8 & 54.5 & 49.0 & 65.6 & 57.9 & 78.9 & 66.8 & $<0.001$ & 59.4 & 51.2 \\
\hline \multicolumn{12}{|l|}{ TZ volume } \\
\hline Ellipsoid & 19.2 & 15.2 & 25.4 & 18.5 & 34.2 & 26.8 & 43.1 & 32.8 & $<0.001$ & 29.1 & 21.2 \\
\hline Prebiopsy PSA & 5.6 & 4.8 & 7.0 & 5.4 & 9.1 & 8.6 & 13.6 & 9.3 & $<0.001$ & 8.3 & 6.3 \\
\hline PSAD & 0.15 & 0.11 & 0.16 & 0.12 & 0.17 & 0.14 & 0.22 & 0.14 & 0.291 & 0.17 & 0.12 \\
\hline TZ PSAD & 0.42 & 0.30 & 0.49 & 0.29 & 0.46 & 0.31 & 0.53 & 0.30 & 0.859 & 0.48 & 0.30 \\
\hline TZ index & 0.42 & 0.37 & 0.41 & 0.40 & 0.46 & 0.48 & 0.50 & 0.51 & 0.017 & 0.44 & 0.42 \\
\hline
\end{tabular}

Abbreviations: PSA, prostate specific antigen; PSAD, prostate specific antigen density; TTMB, transperineal template-guided mapping biopsy;

TZ, transition zone.

${ }^{\text {a}}$ Most recent mapping biopsy.

Bold indicates statistically significant.

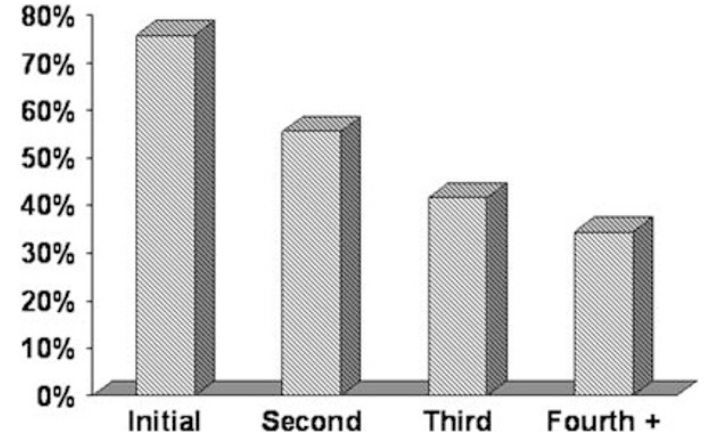

Figure 1 Cancer detection rate (by biopsy session).

Men undergoing repeat biopsies were on average older and had a higher prebiopsy PSA. Table 2 summarizes TTMB parameters of the study population. Men undergoing repeat biopsies had significantly larger prostates, greater TZ volumes, and higher TZ index.

As presented in Figure 1, the cancer detection rate for men undergoing initial biopsy was $75.9 \%$. For men with one, two, and three or more prior negative biopsies detection rates were $55.5 \%, 41.7 \%$, and $34.4 \%$, respectively. Table 3 details cancer detection variables for the men in whom cancer was diagnosed. In all, $55.5 \%$ of the cancers identified were Gleason $\geqslant 7$, with $14.6 \%$ being Gleason $\geqslant 8$. The majority of the cancers were multifocal. In all, $61.1 \%$ of the men diagnosed had $\geqslant 5$ positive cores; and $25.3 \%$ had $>12$ positive cores. There was no significant change in the number of positive cores or in Gleason score as the number of prior biopsies increased.

For men undergoing repeat biopsy, cancer detection rate was $51.6 \%$ for men with persistently elevated PSA (112 of 217 patients), $37.3 \%$ for men with atypical small acinar proliferation (22 of 59 patients), and $22.2 \%$ for men with prostatic intraepithelial neoplasia (4 of 18 patients). Table 4 displays the number of potentially insignificant prostate cancers identified by biopsy session. Overall the rate of potentially insignificant cancers was low (11.1\%), and there was no increase in the number of potentially insignificant cancers identified as the number of biopsies increased.
The location in which Gleason $\geqslant 6$ prostate cancers were identified is presented graphically in Figure $2 a-c$. The highlighted circles represent prostate regions, which frequently ( $>10 \%$ of the time) were found to be involved with cancer. Figure $2 a$ is for men undergoing initial TTMB and shows that all 24 of the regions sampled were frequent sites of cancer. Figure $2 b$ and $c$ display results for men with one and two or more prior negative biopsy who underwent TTMB. As the number of prior biopsies increased, only the most-anterior aspects of the prostate continued to harbor Gleason $\geqslant 6$ cancers. Table 5 provides detail on the cancer detection rate for each region.

\section{Discussion}

For men undergoing initial biopsy with PSA between 4 and $10 \mathrm{ng}$ per $100 \mathrm{ml}$, prostate cancer detection rates are approximately $40-45 \%$ for the standard 12-core TRUS biopsy. 8 Increasing the number of transrectal cores at initial biopsy does not appear to significantly improve yield. ${ }^{10,11}$ Eichler et al. ${ }^{8}$ pooled data from 68 studies and found a significant improvement in cancer detection moving from the standard sextant scheme to a 12-core approach. However, there was no benefit to further increasing the number of cores taken. Lane et al. ${ }^{12}$ recently reported on a cohort of 257 men who underwent saturation biopsy (median of 24 cores) as initial work up. Cancer detection rate $(43 \%)$ and percent of repeat biopsies in which cancer was identified (24\%) were similar to that of men undergoing initial nonsaturation biopsy at their institution. This has been taken as further evidence against saturation biopsy as an initial strategy.

The transperineal approach for initial biopsy does not necessarily result in improved detection rates. Most studies exploring this have used a 'fan technique,' in which all biopsies are obtained through a single perineal skin puncture and no template is used. Although this technique is easier to perform, it lacks the structure of template-guided biopsy. Transperineal biopsies performed in this manner show initial cancer detection rates of approximately $40 \%,{ }^{13}$ very similar to the standard TRUS biopsy. The only reasonably large study ${ }^{4}$ 
Table 3 Characteristics of cancers detected

\begin{tabular}{|c|c|c|c|c|c|c|c|c|c|c|c|}
\hline \multirow[t]{3}{*}{ Continuous variables } & \multicolumn{11}{|c|}{ Number of biopsy sessions } \\
\hline & \multicolumn{2}{|c|}{$1(\mathrm{n}=60)$} & \multicolumn{2}{|c|}{$2(\mathrm{n}=81)$} & \multicolumn{2}{|c|}{$3(\mathrm{n}=35)$} & \multicolumn{2}{|c|}{$\geqslant 4(\mathrm{n}=22)$} & \multirow[t]{2}{*}{$\mathrm{P}$} & \multicolumn{2}{|c|}{ Total $(\mathrm{n}=198)$} \\
\hline & Mean & Median & Mean & Median & Mean & Median & Mean & Median & & Mean & Median \\
\hline Number mapping cores & 54.2 & 54.0 & 55.8 & 57.0 & 53.9 & 58.0 & 54.5 & 58.5 & 0.603 & 54.8 & 56.0 \\
\hline Mean $\%$ positive biopsies & 22.4 & 13.4 & 15.9 & 10.9 & 15.5 & 12.5 & 17.7 & 6.4 & 0.256 & 18.0 & 12.1 \\
\hline \multirow[t]{2}{*}{ Categorical variables } & \multicolumn{11}{|c|}{ Number of patients with prostate cancer } \\
\hline & \multicolumn{2}{|c|}{ Count (\%) } & \multicolumn{2}{|c|}{ Count (\%) } & \multicolumn{2}{|c|}{ Count $(\%)$} & \multicolumn{2}{|c|}{ Count (\%) } & $\mathrm{P}$ & \multicolumn{2}{|c|}{ Count (\%) } \\
\hline \multicolumn{12}{|l|}{ Gleason score } \\
\hline 6 & \multirow{2}{*}{\multicolumn{2}{|c|}{$\begin{array}{l}24(40.0) \\
26(43.3)\end{array}$}} & \multicolumn{2}{|c|}{$38(46.9)$} & \multicolumn{2}{|c|}{$17(48.6)$} & \multicolumn{2}{|c|}{$9(40.9)$} & 0.183 & \multicolumn{2}{|c|}{$88(44.4)$} \\
\hline 7 & & & \multirow{2}{*}{\multicolumn{2}{|c|}{$\begin{array}{c}3 /(7 . /) \\
6(7.4)\end{array}$}} & & & & & & & \\
\hline $8-10$ & \multicolumn{2}{|c|}{$10(16.7)$} & & & \multicolumn{2}{|c|}{$8(22.9)$} & \multicolumn{2}{|c|}{$5(22.7)$} & & \multicolumn{2}{|c|}{$29(14.6)$} \\
\hline \multicolumn{12}{|l|}{ No. positive cores } \\
\hline $1-4$ & \multicolumn{2}{|c|}{$22(36.7)$} & \multicolumn{2}{|c|}{$28(34.6)$} & \multicolumn{2}{|c|}{$14(40)$} & \multicolumn{2}{|c|}{$13(59.1)$} & 0.643 & \multicolumn{2}{|c|}{77 (38.9) } \\
\hline $5-12$ & \multicolumn{2}{|c|}{$21(35.0)$} & \multicolumn{2}{|c|}{$34(42)$} & & 37.1) & & 3.6) & & & 35.8) \\
\hline$>12$ & & 28.3) & 19 & 23.5) & & $2.9)$ & & $7.3)$ & & & 25.3) \\
\hline Prebiopsy diagnosis & & & & & & & & & & & \\
\hline PIN & & (0) & & 3.7) & & 2.9) & & (0) & 0.002 & & $2.0)$ \\
\hline Elevated PSA & & 100) & & 30.2) & & 80.0) & & 86.4) & & & 86.9) \\
\hline ASAP & & (0) & 13 & 16.0) & & 7.1) & & 3.6) & & & 11.1) \\
\hline
\end{tabular}

Abbreviations: ASAP, atypical small acinar proliferation; PIN, prostatic intraepithelial neoplasia; PSA, prostate specific antigen.

Italic indicates significance test.

using a template-guided transperineal approach for initial biopsy in men with PSA from 4 to $10 \mathrm{ng}$ per $100 \mathrm{ml}$, reported a cancer detection rate of $49 \%$ with an average of 18 cores sampled.

In men with an earlier negative biopsy, standard TRUS re-biopsy has a low rate of cancer detection with yields of $10-20 \%$ for the second biopsy, ${ }^{14-16}$ and below $10 \%$ for subsequent biopsies. ${ }^{14,16}$ This has led to increased use for repeat biopsies of a saturation approach sampling 18 to 50 or more cores. Increasing the number of cores does appear to increase detection rate in this setting. However, the cancers diagnosed tend to be smaller and of lower grade. A recent review of the Cleveland Clinic experience found a cancer detection rate of $22 \%$ in men with an earlier negative biopsy. ${ }^{17}$ But Gleason score, percent positive cores, maximum core involvement and bilaterality were significantly lower in cancers found on repeat biopsy. Other large transrectal saturation biopsy series report detection rates of $25-40 \%$ in men with earlier negative biopsies. ${ }^{11,18-20}$ However, two-thirds to three-quarters of the cancers identified in these studies were Gleason score $\leqslant 6,{ }^{18-20}$ supporting the assertion that repeat TRUS biopsy is likely to identify lower grade disease.

In our cohort of men undergoing repeat biopsy with TTMB, we report an overall yield for of $47 \%$. Of the cancers identified with TTMB, over half were Gleason $\geqslant 7$, and $14 \%$ were Gleason 8 or higher. Potentially insignificant cancers represented only $11 \%$ of total. Even in men with three or more prior negative biopsies, TTMB continued to find high-grade, high-volume disease. In these men, cancer detection rate was $34 \% ; 23 \%$ of cancers detected were Gleason 8 or higher; $59 \%$ were Gleason $\geqslant 7$; and $27 \%$ had $\geqslant 13$ cores involved. Potentially insignificant disease represented only $14 \%$ of this heavily presampled cohort. Unlike the reported experience of men undergoing repeat biopsy with transrectal
Table 4 Clinically insignificant prostate cancer

\begin{tabular}{lc}
\hline No. of biopsy sessions & $\begin{array}{c}\text { No. of insignificant prostate } \\
\text { cancers/total cancers }\end{array}$ \\
\hline 1 & $7 / 60(11.7 \%)$ \\
2 & $9 / 81(11.1 \%)$ \\
3 & $3 / 35(8.6 \%)$ \\
$>4$ & $3 / 22(13.6 \%)$ \\
Total & $22 / 198(11.1 \%)$ \\
\hline
\end{tabular}

approach, ${ }^{14,17}$ there was no significant decrease in Gleason score or volume of disease in men undergoing repeat biopsy with TTMB.

The cohort of men in our study undergoing initial biopsy with TTMB is typical of an average risk group referred for first prostate biopsy. Median age was 63.9; median PSA was $4.8 \mathrm{ng}$ per $100 \mathrm{ml}$; and median prostate volume was $45 \mathrm{cc}$. None of the men in this study had an abnormal digital rectal exam (DRE). Using TTMB, we report a cancer detection rate of $75.9 \%$ on initial biopsy. This is significantly higher than the $40-45 \%$ yield expected from standard TRUS biopsy in similar risk men. Of note, $17 \%$ of the cancers identified were Gleason 8 or higher, $60 \%$ were Gleason $\geqslant 7$, and only $12 \%$ represented potentially insignificant disease.

The distribution of cancers identified on initial and subsequent TTMB biopsies provides some insight as to why TTMB seems to have a higher cancer detection rate than other biopsy schemes. For individuals undergoing initial biopsy with TTMB (Figure 2a), cancer was identified frequently in all 24 of our designated biopsy regions. When TTMB was used after one prior negative biopsy (Figure 2b), cancer continued to be identified frequently throughout the entire gland, with the exceptions of regions 3, 4, 12, 13, and 22. Not surprisingly, 
a

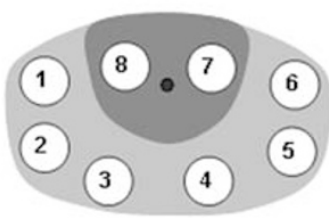

Base

b

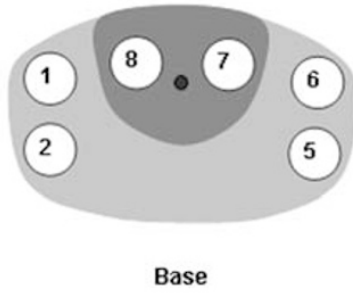

C

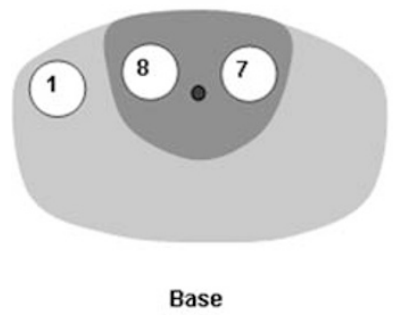

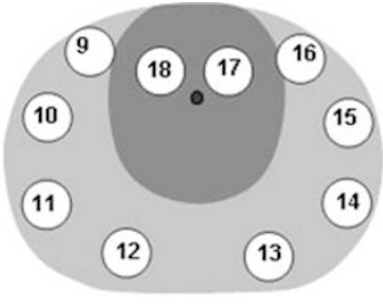

Midgland

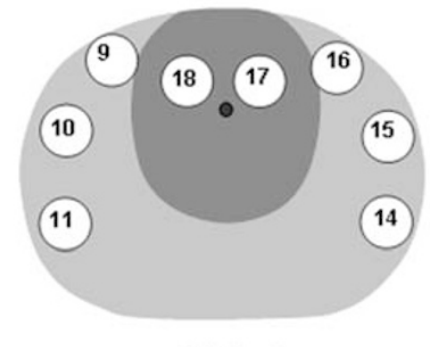

Midgland

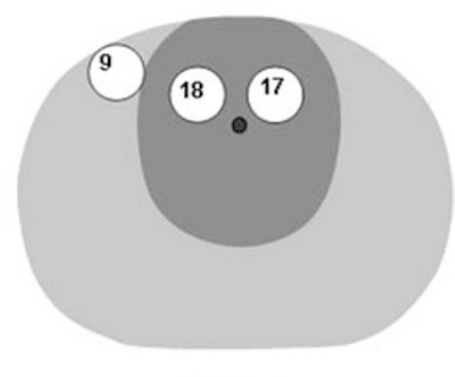

Midgland
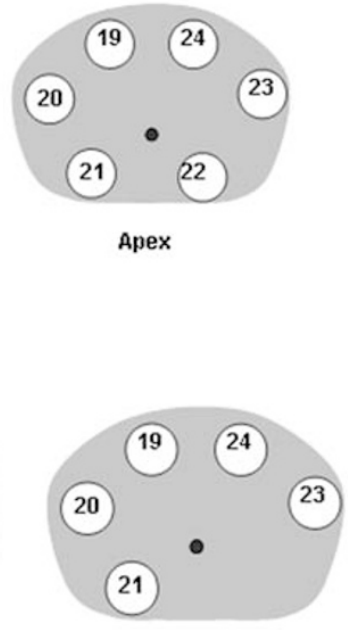

Apex

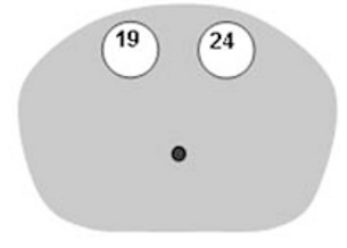

Apex

Figure 2 (a) Initial biopsy: regions with frequent ( $>10 \%$ of men) cancer involvement. (b) One prior negative biopsy: regions with frequent ( $>10 \%$ of men) cancer involvement. (c) Two or more prior negative biopsies: regions with frequent ( $>10 \%$ of men) cancer involvement.

these are the most posterior regions of the prostate and are the regions most easily accessed with a transrectal biopsy.

The above point is more striking when compared with men for whom TTMB was used after two or more earlier negative biopsies (Figure 2c). In these men, the cancer detection rate remained high $(38 \%)$, but the only areas in which cancer was frequently identified were the anterior-most aspects of the gland (regions 1, 8, $7,9,17,18,19,24)$. Presumably, with a large enough number of transrectal cores taken (mean of 37.9 prior cores in men with 3 prior biopsies), cancer closer to the rectum is fairly readily discovered. However, it appears that disease in the anterior prostate, particularly the anterior apex, is not consistently sampled through a transrectal approach.

Our results are favorable when compared with the limited number of studies that have evaluated a transperineal template technique for similar risk men (median PSA 10 or less). Furuno et al. ${ }^{4}$ report using transperineal template-guided approach in the initial biopsy setting and achieved a $49 \%$ cancer detection rate using an average of only 18 cores. In this same study, the group reported a $26 \%$ yield in the repeat biopsy setting, with an average of 19 cores sampled. Satoh et al. ${ }^{21}$ achieved a $22 \%$ yield in men with at least one prior negative biopsy using a 22-core transperineal template scheme. More recently, Moran and Braccioforte ${ }^{22}$ using a transperineal template reported a yield for Gleason $\geqslant 6$ cancer of $38 \%$ in men with prior biopsies, taking an average of 40 cores. On the basis of the above, it appears that the higher yields achieved in this study are related both to the number of cores taken and to the greater, structured access provided with a transperineal template.

As few of these patients went on to prostatectomy, we do not have whole-mount pathologic data to confirm Gleason score, tumor location, and clinical significance. However, our results are in concordance with the results from large prostatectomy series in which whole-mount pathologic evaluation of all cancer foci was available. In particular, our finding on TTMB of high prevalence of periurethral and TZ foci of disease is consistent with prior reports. For instance, Leibovich et al. ${ }^{23}$ after careful evaluation of 350 consecutive prostatectomy specimens found that $84 \%$ of patients had disease within $5 \mathrm{~mm}$ of the urethra. Chen et al. ${ }^{24}$ examined 180 prostatectomy specimens and found that $54 \%$ of patients had foci of disease in the TZ. The location of cancer foci we report is not unexpected. What is notable from this study is the extent to which traditional TRUS biopsy appears to miss a significant portion of periurethral and anterior/apical disease. 
Table 5 Region-specific positive biopsies, stratified by the number of biopsy sessions

\begin{tabular}{|c|c|c|c|c|c|c|c|c|c|c|}
\hline \multirow[t]{2}{*}{ Region } & \multicolumn{10}{|c|}{ Number of biopsy sessions } \\
\hline & \multicolumn{2}{|c|}{$1 \mathrm{n} \%$} & \multicolumn{2}{|c|}{$2 \mathrm{n}(\%)$} & \multicolumn{2}{|c|}{$3 \mathrm{n}(\%)$} & \multicolumn{2}{|c|}{$4+\mathrm{n}(\%)$} & \multicolumn{2}{|c|}{ All n (\%) } \\
\hline \multicolumn{11}{|l|}{ Base } \\
\hline 1 & 15 & $19.0 \%$ & 23 & $15.8 \%$ & 11 & $13.1 \%$ & 9 & $14.1 \%$ & 58 & $15.5 \%$ \\
\hline 2 & 16 & $20.3 \%$ & 19 & $13.0 \%$ & 7 & $8.3 \%$ & 5 & $7.8 \%$ & 47 & $12.6 \%$ \\
\hline 3 & 13 & $16.5 \%$ & 8 & $5.5 \%$ & 4 & $4.8 \%$ & 3 & $4.7 \%$ & 28 & $7.5 \%$ \\
\hline 4 & 11 & $13.9 \%$ & 4 & $2.7 \%$ & 2 & $2.4 \%$ & 1 & $1.6 \%$ & 18 & $4.8 \%$ \\
\hline 5 & 17 & $21.5 \%$ & 19 & $13.0 \%$ & 7 & $8.3 \%$ & 4 & $6.3 \%$ & 47 & $12.6 \%$ \\
\hline 6 & 20 & $25.3 \%$ & 17 & $11.6 \%$ & 7 & $8.3 \%$ & 5 & $7.8 \%$ & 49 & $13.1 \%$ \\
\hline 7 & 10 & $12.7 \%$ & 18 & $12.3 \%$ & 9 & $10.7 \%$ & 8 & $12.5 \%$ & 45 & $12.1 \%$ \\
\hline 8 & 17 & $21.5 \%$ & 21 & $14.4 \%$ & 10 & $11.9 \%$ & 7 & $10.9 \%$ & 55 & $14.7 \%$ \\
\hline \multicolumn{11}{|c|}{ Midgland } \\
\hline 9 & 20 & $25.3 \%$ & 22 & $15.1 \%$ & 10 & $11.9 \%$ & 8 & $12.5 \%$ & 60 & $16.1 \%$ \\
\hline 10 & 17 & $21.5 \%$ & 20 & $13.7 \%$ & 4 & $4.8 \%$ & 6 & $9.4 \%$ & 47 & $12.6 \%$ \\
\hline 11 & 22 & $27.8 \%$ & 19 & $13.0 \%$ & 6 & $7.1 \%$ & 4 & $6.3 \%$ & 51 & $13.7 \%$ \\
\hline 12 & 17 & $21.5 \%$ & 14 & $9.6 \%$ & 8 & $9.5 \%$ & 4 & $6.3 \%$ & 43 & $11.5 \%$ \\
\hline 13 & 17 & $21.5 \%$ & 13 & $8.9 \%$ & 5 & $6.0 \%$ & 2 & $3.1 \%$ & 37 & $9.9 \%$ \\
\hline 14 & 18 & $22.8 \%$ & 18 & $12.3 \%$ & 4 & $4.8 \%$ & 3 & $4.7 \%$ & 43 & $11.5 \%$ \\
\hline 15 & 13 & $16.5 \%$ & 18 & $12.3 \%$ & 5 & $6.0 \%$ & 5 & $7.8 \%$ & 41 & $11.0 \%$ \\
\hline 16 & 14 & $17.7 \%$ & 23 & $15.8 \%$ & 9 & $10.7 \%$ & 5 & $7.8 \%$ & 51 & $13.7 \%$ \\
\hline 17 & 14 & $17.7 \%$ & 18 & $12.3 \%$ & 12 & $14.3 \%$ & 8 & $12.5 \%$ & 52 & $13.9 \%$ \\
\hline 18 & 15 & $17.7 \%$ & 26 & $17.8 \%$ & 8 & $9.5 \%$ & 8 & $12.5 \%$ & 56 & $15.0 \%$ \\
\hline \multicolumn{11}{|l|}{ Apex } \\
\hline 19 & 28 & $35.4 \%$ & 34 & $23.3 \%$ & 16 & $19.0 \%$ & 11 & $17.2 \%$ & 89 & $23.9 \%$ \\
\hline 20 & 23 & $29.1 \%$ & 21 & $14.4 \%$ & 7 & $8.3 \%$ & 4 & $6.3 \%$ & 55 & $14.7 \%$ \\
\hline 21 & 20 & $25.3 \%$ & 16 & $11.0 \%$ & 7 & $8.3 \%$ & 5 & $7.8 \%$ & 48 & $12.9 \%$ \\
\hline 22 & 14 & $17.7 \%$ & 14 & $9.6 \%$ & 6 & $7.1 \%$ & 5 & $7.8 \%$ & 39 & $10.5 \%$ \\
\hline 23 & 14 & $17.7 \%$ & 26 & $17.8 \%$ & 11 & $13.1 \%$ & 3 & $4.7 \%$ & 54 & $14.5 \%$ \\
\hline 24 & 22 & $27.8 \%$ & 37 & $25.3 \%$ & 20 & $23.8 \%$ & 8 & $12.5 \%$ & 87 & $23.3 \%$ \\
\hline
\end{tabular}

\section{Potential implications}

In men who go on to prostatectomy after initial standard TRUS biopsy, studies have found that biopsy Gleason score is upgraded from $30 \%$ to $50 \%$ of the time based on evaluation of the entire prostatectomy specimen. ${ }^{3}$ The prospect of undergrading particularly affects men who are considering a course of close observation for suspected minimal disease identified on biopsy. Epstein et al. ${ }^{7}$ evaluated prostatectomy specimens of 103 men believed to have insignificant cancer based on an initial TRUS biopsy. They found that $29 \%$ of the men had higher-volume and/or higher-grade disease than expected after review of prostatectomy specimens. A negative TTMB may provide reassurance needed to allow men with an initial diagnosis of minimal disease to pursue a course of close observation. As well, a subset of men thought to have insignificant disease may be diagnosed with more aggressive cancers on TTMB and opt for definitive treatment.

On another topic, there is significant interest currently in identifying men who are candidates for focal, rather than whole gland, definitive treatment for their prostate cancers. ${ }^{25}$ Unfortunately, our existing imaging technologies are not yet able to reliably confirm that a patient has unifocal disease. ${ }^{26,27}$ And magnetic resonance imaging, the most successful imaging modality to date, has particular challenges identifying cancers in the prostate TZ. ${ }^{26,28}$ On the basis of our current study and other published work, ${ }^{7}$ even standard TRUS biopsies probably miss an unacceptably high amount of Gleason $\geqslant 6$ cancer to definitively state a man has unifocal disease. TTMB - perhaps in conjunction with evolving imaging technologies-could be used as initial or repeat biopsy to provide reassurance that a patient is a good candidate for segmental rather than whole gland treatment.

\section{Limitations}

This is a retrospective study that reviews our institutional experience with all men undergoing TTMB from January 2005 to September 2008. Although cancer detection yields and proportion of Gleason $\geqslant 7$ disease identified with TTMB is higher than earlier published reports of TRUS biopsies in similar patient groups; this report is not a direct, randomized trial that can definitively answer whether TTMB outperforms TRUS biopsy. Rather, we present this data as hypothesis generating.

TTMB is a more invasive procedure than standard or saturation TRUS biopsy. Although not the focus of this study, we have reported earlier morbidity associated with the procedure. ${ }^{29}$ At our institution, TTMB is associated with a $29 \%$ rate of acute urinary retention and median catheter dependence of one day for men who required catheterization. In our experience, there have been no serious complications, no episodes of sepsis, no impact on erectile function, and no side effects, which were not self-resolving. Tamsulosin was started before TTMB and continued for 2 weeks afterwards. With this prophylaxis, the mean International Prostate Symptom Score (IPSS) before TTMB was 10.4, and was 4.6 and 3.8 at 7 and 30 days. Post-void residual at baseline and 30 days was nearly identical (34.4 and $34.3 \mathrm{ml}) .{ }^{29}$ Physicians along with their patients can assess whether the potentially higher yield from TTMB is worth the more involved procedure.

No doubt there was an element of self-selection in men who opted for the more invasive TTMB-particularly for men undergoing initial biopsy. However, based on PSA level, age, prostate volume, and lack of abnormal DRE, our cohort seems fairly representative of a typical group of men getting initial biopsy. It is not clear that men willing to undergo TTMB for this study (given the other comparable demographic factors) would be more likely to have prostate cancer. However, without a randomized control arm, we cannot state this definitively.

In addition, TTMB is more expensive than a standard TRUS biopsy. At our institution, patients were biopsied under general anesthesia in the operating room (OR). Additional costs included anesthesiology, operating suite, and recovery room expenses that would not be required for an in-office TRUS biopsy. The differences in cost between TTMB and saturation TRUS biopsy are likely less, as saturation TRUS biopsies are often performed under anesthesia.

Finally, even if TTMB has higher yield than standard or saturation TRUS biopsy, it is not obvious that this translates into higher definitive cure rates. The fact that TTMB detection rates remained high after multiple prior TRUS biopsies and that anterior and apical regions of the prostate did not appear to be well sampled with TRUS suggests that at least for some men, their cancer could have gone undetected for some time without TTMB. This may have impacted treatment outcomes, or may not have. To definitively address this issue is well beyond the scope of this study. 


\section{Conclusions}

TTMB provides a high rate of cancer detection as initial biopsy (75.9\%) and as repeat biopsy (46.9\%). Over half of all cancers found were Gleason $\geqslant 7$; and only a small minority of cancers were potentially insignificant $(11.1 \%)$. The distribution of cancers identified in men with multiple prior transrectal biopsies suggests that a template-guided transperineal approach allows better access to the anterior and apical aspects of the gland, in which clinically significant prostate cancer is often located. Increased ability to diagnose apical and anterior disease has implications for men undergoing active surveillance, for men who are considering subtotal prostate gland treatment, for men with initial negative biopsy but persistently elevated PSA, and for men considering minimally invasive treatment options.

\section{Conflict of interest}

The authors declare no conflict of interest.

\section{References}

1 Rabbani F, Stroumbakis N, Kava BR, Cookson MS, Fair WR. Incidence and clinical significance of false-negative sextant prostate biopsies. J Urol 1998; 159: 1247-1250.

2 Singh H, Canto EI, Shariat SF, Kadmon D, Miles BJ, Wheeler TM et al. Predictors of prostate cancer after initial negative systematic 12 core biopsy. J Urol 2004; 171: 1850-1854.

3 Isariyawongse BK, Sun L, Banez LL, Robertson C, Polascik TJ, Maloney K et al. Significant discrepancies between diagnostic and pathologic Gleason sums in prostate cancer: the predictive role of age and prostate-specific antigen. Urology 2008; 72: 882-886.

4 Furuno T, Demura T, Kaneta T, Gotoda H, Muraoka S, Sato T et al. Difference of cancer core distribution between first and repeat biopsy: in patients diagnosed by extensive transperineal ultrasound guided template prostate biopsy. Prostate 2004; 58: 76-81.

5 Emiliozzi P, Scarpone P, DePaula F, Pizzo M, Federico G, Pansadoro A et al. The incidence of prostate cancer in men with prostate specific antigen greater than $4.0 \mathrm{ng} / \mathrm{ml}$ : a randomized study of 6 versus 12 core transperineal prostate biopsy. J Urol 2004; 171: 197-199.

6 Merrick GS, Gutman S, Andreini H, Taubenslag W, Lindert DL, Curtis $\mathrm{R}$ et al. Prostate cancer distribution in patients diagnosed by transperineal template-guided saturation biopsy. Eur Urol 2007; 52: 715-723.

7 Epstein JI, Sanderson H, Carter HB, Scharfstein DO. Utility of saturation biopsy to predict insignificant cancer at radical prostatectomy. Urology 2005; 66: 356-360.

8 Eichler K, Hempel S, Wilby J, Myers L, Bachmann LM, Kleijnen J. Diagnostic value of systematic biopsy methods in the investigation of prostate cancer: a systematic review. J Urol 2006; 175: 1605-1612.

9 Jones JS. Saturation biopsy for detecting and characterizing prostate cancer. BJU Int 2007; 99: 1340-1344.

10 Jones JS, Patel A, Schoenfield L, Rabets JC, Zippe CD, Magi-Galluzzi C. Saturation technique does not improve cancer detection as an initial prostate biopsy strategy. J Urol 2006; 175: 485-488.

11 Pepe P, Aragona F. Saturation prostate needle biopsy and prostate cancer detection at initial and repeat evaluation. Urology 2007; 70: 1131-1135.

12 Lane BR, Zippe CD, Abouassaly R, Schoenfield L, Magi-Galluzzi $\mathrm{C}$, Jones JS. Saturation technique does not decrease cancer detection during followup after initial prostate biopsy. I Urol 2008; 179: 1746-1750; discussion 1750.

13 Galfano A, Novara G, Iafrate M, Cosentino M, Cavalleri S, Artibani $\mathrm{W}$ et al. Prostate biopsy: the transperineal approach. EAU-EBU 2007; 5: 241-249.

14 Djavan B, Ravery V, Zlotta A, Dobronski P, Dobrovits M, Fakhari $\mathrm{M}$ et al. Prospective evaluation of prostate cancer detected on biopsies 1, 2, 3 and 4: when should we stop? J Urol 2001; 166: 1679-1683.

15 Ellis WJ, Brawer MK. Repeat prostate needle biopsy: who needs it? J Urol 1995; 153: 1496-1498.

16 Keetch DW, Catalona WJ, Smith DS. Serial prostate biopsies in men with persistently elevated serum prostate specific antigen values. J Urol 1994; 151: 1571-1574.

17 Tan N, Lane BR, Li J, Moussa AS, Soriano M, Jones JS Prostate cancers diagnosed at repeat biopsy are smaller and less likely to be high grade. J Urol 2008; 180: 1325-1329; discussion 1329.

18 Rabets JC, Jones JS, Patel A, Zippe CD. Prostate cancer detection with office based saturation biopsy in a repeat biopsy population. J Urol 2004; 172: 94-97.

19 Stewart CS, Leibovich BC, Weaver AL, Lieber MM. Prostate cancer diagnosis using a saturation needle biopsy technique after previous negative sextant biopsies. J Urol 2001; 166: 86-91; discussion 91-82.

20 Walz J, Graefen M, Chun FK, Erbersdobler A, Haese A, Steuber $\mathrm{T}$ et al. High incidence of prostate cancer detected by saturation biopsy after previous negative biopsy series. Eur Urol 2006; 50: 498-505.

21 Satoh T, Matsumoto K, Fujita T, Tabata K, Okusa H, Tsuboi T et al. Cancer core distribution in patients diagnosed by extended transperineal prostate biopsy. Urology 2005; 66: 114-118.

22 Moran BJ, Braccioforte MH. Stereotactic transperineal prostate biopsy. Urology 2009; 73: 386-388.

23 Leibovich BC, Blute ML, Bostwick DG, Wilson TM, Pisansky TM, Davis BJ et al. Proximity of prostate cancer to the urethra: implications for minimally invasive ablative therapies. Urology 2000; 56: 726-729.

24 Chen ME, Johnston DA, Tang K, Babaian RJ, Troncoso P. Detailed mapping of prostate carcinoma foci: biopsy strategy implications. Cancer 2000; 89: 1800-1809.

25 Eggener SE, Scardino PT, Carroll PR, Zelefsky MJ, Sartor O, Hricak $\mathrm{H}$ et al. Focal therapy for localized prostate cancer: a critical appraisal of rationale and modalities. J Urol 2007; 178: 2260-2267.

26 Kirkham AP, Emberton M, Allen C. How good is MRI at detecting and characterising cancer within the prostate? Eur Urol 2006; 50: 1163-1174; discussion 1175.

27 Weinreb JC, Blume JD, Coakley FV, Wheeler TM, Cormack JB, Sotto CK et al. Prostate cancer: sextant localization at MR imaging and MR spectroscopic imaging before prostatectomyresults of ACRIN prospective multi-institutional clinicopathologic study. Radiology 2009; 251: 122-133.

28 Akin O, Sala E, Moskowitz CS, Kuroiwa K, Ishill NM, Pucar D et al. Transition zone prostate cancers: features, detection, localization, and staging at endorectal MR imaging. Radiology 2006; 239: 784-792.

29 Merrick GS, Taubenslag W, Andreini H, Brammer S, Butler WM, Adamovich $\mathrm{E}$ et al. The morbidity of transperineal template-guided prostate mapping biopsy. BJU Int 2008; 101: 1524-1529. 